\title{
Social Ecological Model and Underage Drinking: A Theoretical Review and Evaluation
}

\author{
Hamzah M. Alghzawi ${ }^{*}$, Fatima K. Ghanem² \\ ${ }^{1}$ Medstar Good Samaritan Hospital, Maryland, USA \\ ${ }^{2}$ Al Albayt University, Mafraq, Jordan \\ Email: ^hamzahjordan87@umaryland.edu, „hamzahjordan87@gmail.com
}

How to cite this paper: Alghzawi, H. M., \& Ghanem, F. K. (2021). Social Ecological Model and Underage Drinking: A Theoretical Review and Evaluation. Psychology, 12, 817-828.

https://doi.org/10.4236/psych.2021.125050

Received: March 26, 2021

Accepted: May 28, 2021

Published: May 31, 2021

Copyright (c) 2021 by author(s) and Scientific Research Publishing Inc. This work is licensed under the Creative Commons Attribution International License (CC BY 4.0).

http://creativecommons.org/licenses/by/4.0/

\begin{abstract}
Social Ecological Model (SEM) is a theoretical framework using a comprehensive approach to assess or change human behavior. This article aims at evaluating the SEM according to Fawcett criteria, and then discusses its appropriateness to be used as a theoretical framework for a study on underage drinking. A comprehensive search was conducted using PubMed, Google Scholar, EBSCO, CINAHL, and Ovid Journal databases. It was found that SEM has a social and theoretical significance in nursing field. It consistently states its concepts and assumptions without redundancy. SEM has been tested by several studies, and the findings of these studies were congruent with SEM's assumptions. SEM helps in a better understanding of underage drinking, and then tailoring comprehensive prevention programs to tackle this problem.
\end{abstract}

\section{Keywords}

Underage Drinking, Social Ecological Model, Concept, Assumption, Values, Parsimony, Testability, Empirical Adequacy, Pragmatic Adequacy, Fawcett

\section{Introduction}

Underage drinking is a serious public health concern. Every day in the United States, more than 4750 children under age 16 have their first full drink of alcohol (SAMHSA, 2019). In 2019, almost 24.6 percent of children ages 14 to 15 year-old reported having at least 1 drink. Moreover, almost 2 out of 100 children ages 12 to 13 reported drinking alcohol in the past month and fewer than 1 in 100 engaged in binge drinking (SAMHSA, 2019). It is widely acknowledged that underage drinking is associated with negative medical and social consequences among underage drinkers (Carpenter \& Merrill, 2021; Morean, Peterson, \& L'Insalata, 
2019; Smit et al., 2018). To develop and implement effective prevention and intervention programs for underage drinking, it is necessary to understand the predictors of underage drinking (Morean et al., 2019).

Several studies have examined predictors of underage drinking (Alghzawi et al., 2014a; Morean et al., 2019; Trucco, 2020). Predictors of underage drinking could be divided into individual factors (e.g., alcohol-related cognitions, personality, and behavioral) and environmental factors (e.g., family, peers, and media) (Smit et al., 2018). Since underage drinking is a multifaceted behavior which influences are drawn from various sources, the social ecological model (SEM) is highly recommended theoretical model to better understanding this behavior (Alghzawi, 2012; Alghzawi et al., 2014a, 2014b, 2014c; Scheier, 2001).

Literature search revealed limited use of other models and theories, such as the stages of change model (Prochaska \& DiClemenet, 1982) and self-efficacy theory (Bandura, 1977, 1997) to explain the behavior of alcohol use. While these theoretical frameworks are still useful, they merely focus on the individual and the psychology of the change process and do not take into consideration the multiple factors that influence children's behaviors, such as the social environment, interpersonal factors, and public policy. This confirms that SEM is the most appropriate model for a topic such as underage drinking. This article aims to evaluate the SEM according to Fawcett criteria, and then discuss its appropriateness to be used as a theoretical framework for a study on underage drinking.

\section{Methods}

A comprehensive search was conducted using PubMed, Google Scholar, EBSCO, CINAHL, and Ovid Journal databases. The online search process was carried out using general terms, such as "underage drinking," "social ecological model," "concept," “assumption," "values," “parsimony," “testability”, “empirical adequacy," "pragmatic adequacy," and "Fawcett".

\section{Results}

\subsection{An Overview of Social Ecological Model}

SEM is a comprehensive approach to explain individual's behaviors. The term ecology originates in the biological sciences and refers to the interrelationships between organisms and their environments. SEM has evolved over a number of decades in the fields of sociology, psychology, education, and health. It focuses on the nature of people's interactions with their environments (Bronfenbrenner, 1994). This model suggests that behavior is affected by multiple levels of influence (McLeroy et al., 1988).

SEM developed out of the work of three prominent researchers. Initially, Urie Bronfenbrenner (1994) developed the ecological systems theory, which focused on the relationship between the individual and the environment. Then, Kenneth McLeroy et al. (1988) developed the ecological model of health behaviours which 
classified five different levels of influence on health behaviour. Lastly, Daniel Stokols (1992), who developed the social ecology model of health promotion, identified the core assumptions that underpin the social-ecological model (Glanz et al., 2008).

SEM provides a set of conceptual and methodological principles, drawn mainly from systems theory, for organizing comprehensive, community-based promotion initiatives (Glanz, Lewis, \& Rimer, 1997). SEM is multifaceted, targeting individual, environmental, behavioral, and social policy changes that help individuals make health choices in their daily lives. SEM is unique in that it takes into account the physical environment and its relationship to people at intrapersonal, interpersonal, organizational, community, and public policy levels. This perspective is based on the major philosophical construct of the SEM that behavior does not occur in nothings (Glanz, Lewis, \& Rimer, 1997). Literature search demonstrated that SEM provides promising results in preventing many public health problems, such as alcohol and tobacco use; however, additional research should be directed to applying this model to other public health problems (Alghzawi, 2018; Breslow, 1996; Jamner \& Stokols, 2000; Richard et al. 1996).

A major principle in SEM is reciprocal determinism or the interaction between the individual's behavior and the surrounding environment. Reciprocal determinism is a concept originally identified by Bandura (1977) in social cognitive theory. It means that the environment largely controls behavior and over time changing environmental variables lead to modification of behavior (Green, Richard, \& Potvin, 1996).

\subsection{Major Concepts}

As shown in Figure 1, the core concept of SEM is that behavior has multiple levels of influences, often including intrapersonal level (biological, psychological),

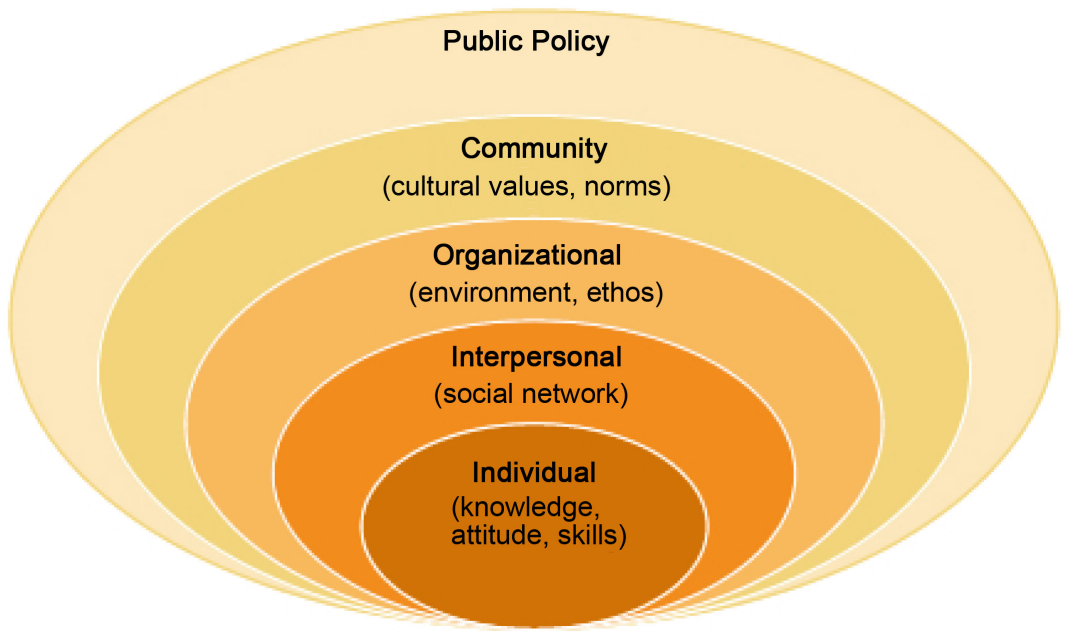

Figure 1. The social ecological model: A framework for prevention. Source: Adapted from the centers for Disease Control and Prevention (CDC).

http://www.cdc.gov/violenceprevention/overview/social-ecologicalmodel.html (retrieved April 21, 2021). 
interpersonal level (social, cultural), organizational level, community level, and policy level. Table 1 provides a brief description of SEM's levels. These levels are summarized as follows:

1) The intrapersonal level (Individual level) of the social ecological model takes into accounts an individual's knowledge, attitudes, values, skills, self-concept, and self-confidence. Strategies that bring change at the individual level tend to focus on changing an individual's knowledge, attitudes, behaviour, and skills. They include education and mentoring programs, mass media campaigns, social marketing, and skills development (McLeroy et al., 1988).

2) The interpersonal level includes an individual's social networks, social supports, families, work groups, peers, and neighbors. Intervention strategies at this level include enhancement of social supports and social networks, changing group norms, and increasing access (McLeroy et al., 1988).

3) The organizational level includes organisational characteristics of social institutions, organizational culture and structure, management styles, and educational institutions. Intervention strategies at this level include incentive programs, process consultation, coalition development, and agency linkage (McLeroy et al., 1988).

4) The community level includes community resources, neighborhood, social and health services, folk practices, community leaders, businesses, and transportation. Intervention strategies at this level include community development, community coalitions, empowerment, conflict resolution, and mass media campaigns (McLeroy et al., 1988).

5) The public policy level includes legislation, policies, taxes, and regulatory agencies. Strategies to intervene at this level include mass media campaigns, policy analysis, political change, and lobbying (McLeroy et al., 1988).

Table 1. Summarized levels of influences according to SEM.

\begin{tabular}{ll}
\hline Level of influence & \\
\hline $\begin{array}{l}\text { Intrapersonal } \\
\text { Individual, personal }\end{array}$ & $\begin{array}{l}\text { Individual characteristics that influence behavior: } \\
\text { Knowledge, self-confidence, skill, etc. }\end{array}$ \\
$\begin{array}{l}\text { Interpersonal } \\
\text { Family, friends, } \\
\text { peers }\end{array}$ & $\begin{array}{l}\text { Interpersonal processes and groups providing identity } \\
\text { and support }\end{array}$ \\
$\begin{array}{l}\text { Organizational } \\
\text { Churches, Mosque, } \\
\text { schools }\end{array}$ & $\begin{array}{l}\text { Rules, regulation, policies, structures constraining } \\
\text { or promote behaviors }\end{array}$ \\
$\begin{array}{l}\text { Community } \\
\text { Social networks }\end{array}$ & $\begin{array}{l}\text { Community norms (community regulations) } \\
\text { Public policy }\end{array}$ \\
\hline $\begin{array}{l}\text { Local, state, federal } \\
\text { practices/actions }\end{array}$
\end{tabular}




\subsection{Belief, Assumptions, and Values}

\subsubsection{Assumption}

Many factors within five levels influence individual's behaviours. Therefore, efforts to assess or change behaviour should be based on the understanding of the interrelationship between the five levels of the SEM; intrapersonal level, interpersonal level, organizational level, community level and policy level. Assessment of individual's behaviour and interventional programs are more likely to be effective when they target multiple components of the SEM (Stokols, 1992).

Environments are multidimensional and complex. Social or physical environments can be described as containing a variety of features or attributes, such as the size, temperature, facilities and safety. Environments can also be described in terms of their actual or perceived qualities. The variable nature of environments has a direct implication on the design of initiatives to promote human behaviour (Stokols, 1992).

Human-environment interactions can be described at varying levels of organisation. Human interactions with the environment can occur at individual, small group, organisational, community or population levels. The SEM does not just focus on the individual but includes multiple levels of human interaction with environments. For example, interventions promoting human behaviour can be large such as whole population mass media campaigns or may focus on organisations such as school settings or may be based around a local community which they are tailored to. The effectiveness of campaigns to promote human behaviour is enhanced when they target differing levels of the human-environment interaction (Stokols, 1992).

The interrelationships between people and their environment are dynamic. There is a reciprocal relationship between people and their environments. The social, physical and policy environments influence the behaviour of the individual, while at the same time behaviour of the individual, group or organisation also impact on the wellbeing of their environments. The environment can control or set limits to human behaviour that occurs within it. Making a change in the environment can result in a modification of behaviour (Jamner \& Stokols, 2000; Stokols, 1992).

\subsubsection{Beliefs}

- Comprehensive assessment of specific individual's behavior should cover the all multi levels of influences, including the intrapersonal, interpersonal, organizational, community, and public policy levels.

- Influences on behaviors interact across these different levels.

- The ultimate purpose of the SEM is to inform the development of comprehensive intervention approaches that can systematically target mechanisms of change at several levels of influence.

- Behavior change is expected to be maximized when environments and policies support healthful choices, when social norms and social support for healthful choices are strong, and when individuals are motivated and educated to 
make those choices.

\subsubsection{Values}

- It is important to assess multifaceted behaviors such as underage drinking based on a comprehensive model such as SEM.

- It important to establish prevention and promotion programs that target all levels of influences on children's behavior.

- Health care providers should commit to SEM's assumptions when they deal with patient has multifaceted behavior such as alcohol use.

- Nurses should equally cover all levels of influences when they assess patient's behavior and not just focusing on specific level and ignoring others.

\subsection{Evaluation of SEM Using Fawcett Criteria}

\subsubsection{Significance}

The significance criterion requires the model to reflect social significance and theoretical significance (Fawcett, 2005). Social significance is evident when a theory or a model addresses a problem of particular interest to society (Fawcett, 2005). SEM is a socially significant model because it had a broad use in nursing field, specifically, in predicting the individual's behaviour and in health promotion. It addressed problems of particular interest to society such as the alcohol use problem, the obesity problem, and the risk factors associated with HIV (Katherine, Quinn, \& Thompson, 2004; Yu \& Stiffman, 2007; Erika, 2008; Brown, 2011; Gruenewald, Remer, \& LaScala, 2013). On the other side, theoretical significance is evident when the model addresses a phenomenon of interest to the nursing discipline either by extending the knowledge or filling gaps in an existing theory about the phenomenon (Fawcett, 2005). The SEM met the criterion of theoretical significance as evidenced by addressing assumptions extended and filled gaps in the previous theories such as self-efficacy theory (Bandura, 1977, 1997).

\subsubsection{Internal Consistency}

The internal consistency of the model can be evaluated through three major requirements: semantic clarity, semantic consistency, and structural consistency (Fawcett, 2005). Semantic clarity is met; as evident by providing the core concept of a social ecological model which is multiple levels of influences, often including intrapersonal (biological, psychological), interpersonal (social, cultural), organizational, community, physical environmental, and policy. These levels have a reciprocal relationship between them. Semantic consistency is also met; as evident by consistent use of the same concepts and the same definitions in the model's discussions. Structural consistency is also met; the linkages between concepts are specified and no contradictions in the relationships are evident. These linkages clearly implicate that the levels of influence are interrelated and the reciprocal relationship exists between them.

\subsubsection{Parsimony}

The model is parsimonious when its content is stated clearly without redundan- 
cy (Fawcett, 2005). The model is parsimonious because it states the assumptions with the minimal number of concepts and without oversimplifying or redundancy. The model categorises all factors that could affect on human behaviour into just five levels and it is easy for the readers to classify any factor into one of these levels. For example, it is easy to recognize that self-confidence is one of the intrapersonal factors that affects and affected by the other levels of influences.

\subsubsection{Testability}

The model is testable when its concepts can be can be observed empirically, proposition can be measured, and its derived hypothesis can be falsified (Fawcett, 2005). Several researches have tested SEM. For example, Gruenewald et al. (2013) conducted a study on alcohol users from 50 cities in California, and this study aimed to test the SEM. They found that community availability of alcohol and individual drinker characteristics appear to act jointly to affect drinking levels and use of drinking contexts. This study is a good example on the studies that test SEM, and the congruency between its findings and SEM's assumption confirms the fitness of this model.

\subsubsection{Empirical Adequacy}

This criterion requires the assumptions made by the model to be congruent with empirical evidence (Fawcett, 2005). Empirical adequacy is met by SEM because its assumptions are congruent with the findings of all studies used this model as a theoretical framework. For example, Yu and Stiffman (2007) conducted a study using SEM to investigate the cultural and environmental predictors for alcohol abuse and dependence in American Indian people. In addition, Erika (2008) conducted a study using the social ecological model to understand the contextual factors associated with HIV risk in commercial sex workers at high risk for contracting HIV. In general, the findings of these studies were congruent with the SEM's assumption that human behaviour is affected by interrelated multilevel influences.

\subsubsection{Pragmatic Adequacy}

The criterion of pragmatic adequacy focuses on the utility of the theory for nursing practice (Fawcett, 2005). SEM met the criterion of pragmatic adequacy because it was used in the real word of nursing practice and the model's assumptions were utilized in the practice. This conclusion was supported by several studies used SEM in assessing the risk factors for underage drinking and tailoring interventional prevention programs to limit this problem. Moreover, the model's assumptions were utilized in other fields of nursing such as developing prevention programs for alcohol spectrum disorders (Katherine, Quinn, \& Thompson, 2004) and tailoring interventional programs for obesity (Brown, 2011).

\section{Discussion}

Underage drinking is a multifaceted problem that is caused by many factors, and SEM is the most comprehensive model to guide studies related to this topic. The 
literature search revealed several studies that support using SEM to better understand the substance use problem, including alcohol, in which characteristics of the individual, as well as those of the family, peer, community, organization, and policy domains influence the likelihood of such involvement (Hawkins, Catalano, \& Miller, 1992; Petraitis, Flay, \& Miller, 1995; Scheier, 2001). Sociodemographic and individual characteristics play an important role in shaping individual decisions to engage in alcohol use (Petraitis et al., 1995). Several studies on the risk factors of alcohol use highlight the influence of demographic differences, such as gender and age (Alghzawi, 2016a, 2016b, 2016c; Hawkins et al., 1992; Johnston et al., 2006; Scheier, 2001). Other factors, such as depressive symptoms (Armstrong \& Costello, 2002), behavioral problems (Alghzawi, 2018; Alghzawi \& Ghanem, 2021a, 2021b; Farrell et al., 2005), and academic ability (Fothergill \& Ensminger, 2006) are important intrapersonal influences on alcohol use.

The social influences of family and peers are among the most frequently studied risk or protective factors associated with underage drinking (Petraitis et al., 1995). Perceived parental and peer disapproval are significant influences within the interpersonal level (Nash, McQueen, \& Bray, 2005; Windle, 2000). Other interpersonal factors predicting underage drinking use are parental alcoholism (King \& Chassin, 2007; Wong et al., 2004), greater parental drinking (Hawkins et al., 1997), maternal drinking and smoking (Hayatbakhsh et al., 2008), lower parental monitoring (Hayatbakhsh et al., 2008; Rose et al., 2001), worse home environment (Rose et al., 2001), family disruption (Hayatbakhsh et al., 2008), having more friends who drink (Hawkins et al., 1997), and greater exposure to alcohol use in the movies (Sargent et al., 2006).

Furthermore, several studies examined the effect of factors within organizational level, such as school and religious places on alcohol use among children. For example, Yan et al. (2008) tested a structural model explaining the effects of school connectedness on alcohol use among a sample of Latino children aged 11 13. They found that school connectedness had a direct effect, as well as an indirect effect mediated through self-concept and peer norms related to drinking alcohol. This mediating role of peer's norm between school's effect and drinking alcohol confirms the interrelationship between and organizational level the interpersonal level.

Features of the surrounding community influence children's attitudes and behaviors regarding alcohol use. Several studies emphasized the role of children's perceptions of community disorganization, high rates of substance use, and the ready availability of substances within their community as risk factors for engaging in substance use. Research has shown that such community-level characteristics are associated with underage drinking (Bond et al., 2005; Jessor et al., 2003).

Finally, policy factors play a significant effect on childhood alcohol use. The countries could decrease the prevalence of underage drinking through establishing policies and laws that forbidden alcohol selling for children under 18 
years old and also forbidden alcohol use in the public place. Vanessa et al. (2014) reported that when the USA passed more laws aimed at limiting underage drinking between 2005 and 2011, children drinking declined. This finding highlights the significant role of policies and laws to prevent alcohol use problem.

\section{Conclusion}

SEM is theoretical framework using a comprehensive approach to assess or change human behavior. The core concept of SEM is that behavior is multifaceted and has multiple levels of influences, including intrapersonal level, interpersonal level, organizational level, community level, and policy level.

This article evaluated SEM using the Six Fawcett criteria. It was concluded that SEM has a social and theoretical significance in nursing field. It consistently states its concepts and assumptions without redundancy. SEM has been tested by several studies, and the findings of these studies were congruent with SEM's assumptions. SEM has been utilized in several areas in nursing.

This article also discussed prior research used SEM as a theoretical guide to examine the risk factors for underage drinking. The majority of prior research has focused on the effect of individual's characteristics, family, peers, schools, community, and policy on underage drinking. The findings of prior research were congruent with SEM's assumptions. Prior research studies support using SEM to examine other predictors for underage drinking, such as self-confidence, social assertiveness, and self-efficacy. Overall, SEM helps in a better understanding of underage drinking, and then tailoring comprehensive preventing programs to tackle this problem.

\section{Conflicts of Interest}

The authors declare that the research was conducted in the absence of any commercial or financial relationships that could be construed as a potential conflict of interest.

\section{References}

Alghzawi, H. (2016a). Arguments for Using Animals in Research Projects: An Ethical Consideration. Journal of Global Research in Education and Social Science, 8, 205-210. https://ikprress.org/index.php/JOGRESS/article/view/2639

Alghzawi, H. (2016b). Cultural Impact on Mental Health Care in Saudi Arabia. Journal of International Research in Medical and Pharmaceutical Sciences, 10, 127-132. https://www.ikprress.org/index.php/JIRMEPS/article/view/3212

Alghzawi, H. (2016c). The Impact of Domestic Violence on Pregnant Women: A Review Article. Journal of Disease and Global Health, 8, 153-162. https://www.ikprress.org/index.php/JODAGH/article/view/2714

Alghzawi, H. (2018). Probability and Correlates of Nicotine Dependence among Smokers with and without Major Depressive Disorder: Results from the National Epidemiology Survey on Alcohol and Related Conditions. Perspectives in Psychiatric Care, 54, 354-364. https://doi.org/10.1111/ppc.12255

Alghzawi, H. M. (2012). Psychiatric Discharge Process. ISRN Psychiatry, 2012, Article ID: 
638943. https://doi.org/10.5402/2012/638943

Alghzawi, H. M., Hourani, R. A., Alrashaida, B. M., Hamdan-Mansour, A., \& Bayomi, M. (2014a). Discharge Policy Analysis in Prince Hamzah Hospital. Health, 6, 3022-3029. https://doi.org/10.4236/health.2014.621340

Alghzawi, H., ALBashtawy, M., Azzeghaiby, S., \& Alzoghaibi, I. (2014b). The Impact of Wars and Conflicts on Mental Health of Arab Population. International Journal of Humanities and Social Science, 4, 237-242.

Alghzawi, H., ALBashtawy, M., Azzeghaiby, S., \& Azzeghaiby, I. (2014c). Alcohol Use among Adolescents. International Journal of Humanities and Social Science, 4, 167-175.

Alghzawi, M. H., \& Ghanem, K. F. (2021a). A Journal Article Critique of "Motivational Interviewing and Exercise Program for Community-Dwelling Older Persons with Chronic Pain. Open Access Library Journal, 5.

Alghzawi, M. H., \& Ghanem, K. F. (2021b). The Lobotomist: A Maverick Medical Genius and His Tragic Quest to Rid the World of Mental Illness by Jack El-Hai: A Book Review. Voice of the Publisher, 7.

Armstrong, T. D., \& Costello, E. (2002). Community Studies on Adolescent Substance Use, Abuse or Dependence and Psychiatric Comorbidity. Journal of Consulting and Clinical Psychology, 70, 1224-1239. https://doi.org/10.1037/0022-006X.70.6.1224

Bandura, A. (1977). Social Learning Theory. Englewood Cliffs, NJ: Prentice-Hall.

Bandura, A. (1997). Self-Efficacy: The Exercise of Control. New York, NY: W. H. Freeman.

Bond, L., Toumbourou, J., Thomas, L., Catalano, R., \& Patton, G. (2005). Individual, Family, School, and Community Risk and Protective Factors for Depressive Symptoms in Adolescents: A Comparison of Risk Profiles for Substance Use and Depressive Symptoms. Prevention Science, 6, 73-88. https://doi.org/10.1007/s11121-005-3407-2

Breslow, L. (1996). Social Ecological Strategies for Promoting Health Lifestyles. American Journal of Health Promotion, 10, 253-257. https://doi.org/10.4278/0890-1171-10.4.253

Bronfenbrenner, U. (1994). Ecological Models of Human Development. In International Encyclopedia of Education. Oxford: Elsevier.

Brown, S. (2011). Using a Social-Ecological Model to Examine Obesity Interventions Susan Lee Brown. http://lib.dr.iastate.edu/etd

Carpenter, R. W., \& Merrill, J. E. (2021). How Much and How Fast: Alcohol Consumption Patterns, Drinking-Episode Affect, and Next-Day Consequences in the Daily Life of Underage Heavy Drinkers. Drug and Alcohol Dependence, 218, Article ID: 108407. https://doi.org/10.1016/j.drugalcdep.2020.108407

Erika, L. (2008). Using the Social Ecological Model to Understand the Contextual Factors Associated with HIV Risk in Commercial Sex Workers at High Risk for Contracting $H I V$. http://escholarship.org/uc/item/2v458155

Farrell, A. D., Sullivan, T. N., Esposito, L. E., Meyer, A. L., \& Valois, R. F. (2005). A Latent Growth Curve Analysis of the Structure of Aggression, Drug Use, and Delinquent Behaviors and Their Interrelations over Time in Urban and Rural Adolescents. Journal of Research on Adolescence, 15, 179-204.

https://doi.org/10.1111/j.1532-7795.2005.00091.x

Fawcett, J. (2005). Criteria for Evaluation of Theory. Nursing Science Quarterly, 18, 131-135. https://doi.org/10.1177/0894318405274823

Fothergill, K. E., \& Ensminger, M. E. (2006). Childhood and Adolescent Antecedents of Drug and Alcohol Problems: A Longitudinal Study. Drug and Alcohol Dependence, 82, 61-76. https://doi.org/10.1016/j.drugalcdep.2005.08.009

Glanz, K., Lewis, M. L., \& Rimer, B. K. (1997). Health Behavior and Health Education. 
San Francisco, CA: Jossey-Bass.

Glanz, K., Rimer, B. K., \& Viswanath, K (Eds.) (2008). Health Behaviour and Health Education-Theory, Research and Practice (4th ed.). San Francisco, CA: John Wiley and Sons.

Green, L., Richard, L., \& Potvin, L. (1996). Ecological Foundations of Health Promotion. American Journal of Health Promotion, 10, 270-281.

https://doi.org/10.4278/0890-1171-10.4.270

Gruenewald, P., Remer, L., \& LaScala, E. (2013). Testing a Social Ecological Model of Alcohol Use: The California 50-City Study. Addiction, 109, 736-745.

https://doi.org/10.1111/add.12438

Hawkins, J. D., Catalano, R. F., \& Miller, J. Y. (1992). Risk and Protective Factors for Alcohol and Other Drug Problems in Adolescence and Early Adulthood: Implications for Substance Abuse Prevention. Psychological Bulletin, 112, 64-105.

https://doi.org/10.1037/0033-2909.112.1.64

Hawkins, J. D., Graham, J. W., Maguin, E., Abbott, R., Hill, K. G., \& Catalano, R. F. (1997). Exploring the Effects of Age of Alcohol Use Initiation and Psychosocial Risk Factors on Subsequent Alcohol Misuse. Journal of Studies on Alcohol, 58, 280-290. https://doi.org/10.15288/jsa.1997.58.280

Hayatbakhsh, M. R., Mamun, A. A., Najman, J. M., O'Callaghan, M. J., Bor, W., \& Alati, R. (2008). Early Childhood Predictors of Early Substance Use and Substance Use Disorders: Prospective Study. Australian and New Zealand Journal of Psychiatry, 42, 720731. https://doi.org/10.1080/00048670802206346

Jamner, M. S., \& Stokols, D. (2000). The Social Ecological Paradigm of Wellness Promotion in Promoting Human Wellness: New Frontiers for Research, Practice and Policy. Berkeley, Los Angeles, London: University of California Press.

Jessor, R., Turbin, M. S., Costa, F. M., Dong, Q., Zhang, H., \& Wang, C. (2003). Adolescent Problem Behavior in China and the United States: A Cross-National Study of Psychosocial Protective Factors. Journal of Research on Adolescence, 13, 329-360. https://doi.org/10.1111/1532-7795.1303004

Johnston, L. D., O’Malley, P. M., Bachman, J. G., \& Schulenberg, J. E. (2006). Monitoring the Future National Survey Results on Drug Use, Use, 1975-2005: Volume I, Secondary School Students (NIH Publication No. 06-5883). Bethesda, MD: National Institute on Drug Abuse.

Katherine, M., Quinn, L., \& Thompson, S. (2004). A Social Ecological Analysis of Fetal Alcohol Spectrum Disorders Prevention Programming. Journal of FAS international, 2, e11.

King, K. M., \& Chassin, L. (2007). A Prospective Study of the Effects of Age of Initiation of Alcohol and Drug Use on Young Adult Substance Dependence. Journal of Studies on Alcohol and Drugs, 68, 256-265. https://doi.org/10.15288/jsad.2007.68.256

McLeroy, K., Bibeau, D., Steckler, A., \& Glanz, K. (1988). An Ecological Perspective on Health Promotion. Health Education Quarterly, 15, 351-377.

https://doi.org/10.1177/109019818801500401

Morean, M. E., Peterson, J., \& L'Insalata, A. (2019). Predictors of Quickly Progressing from Initiating Alcohol Use to Engaging in Binge Drinking among Adolescents. Addictive Behaviors Reports, 9, Article ID: 100165. https://doi.org/10.1016/j.abrep.2019.100165

Nash, S. G., McQueen, A., \& Bray, J. H. (2005). Pathways to Adolescent Alcohol Use: Family Environment, Peer Influence, and Parental Expectations. Journal of Adolescent Health, 37, 19-28. https://doi.org/10.1016/j.jadohealth.2004.06.004 
Petraitis, J., Flay, B. R., \& Miller, T. Q. (1995). Reviewing Theories of Adolescent Substance Use: Organizing Pieces in the Puzzle. Psychological Bulletin, 117, 67-86. https://doi.org/10.1037/0033-2909.117.1.67

Prochaska, J. O., \& DiClemente, C. C. (1982). Transtheoretical Therapy: Toward a More Integrative Model of Change. Psychotherapy: Theory, Research \& Practice, 19, 276. https://doi.org/10.1037/h0088437

Richard, L., Potvin, L., Kishchuk, N., Prlic, L., \& Green, L. W. (1996). Assessment of the Integration of the Ecological Approach in Health Promotion Programs. American Journal of Health Promotion, 10, 318-328. https://doi.org/10.4278/0890-1171-10.4.318

Rose, R. J., Dick, D. M., Viken, R. J., Pulkkinen, L., \& Kaprio, J. (2001). Drinking or Abstaining at Age 14? A Genetic Epidemiological Study. Alcoholism: Clinical and Experimental Research, 25, 1594-1604. https://doi.org/10.1111/j.1530-0277.2001.tb02166.x

Sargent, J. D., Wills, T. A., Stoolmiller, M., Gibson, J., \& Gibbons, F. X. (2006). Alcohol Use in Motion Pictures and Its Relation with Early-Onset Teen Drinking. Journal of Studies on Alcohol, 67, 54-65. https://doi.org/10.15288/jsa.2006.67.54

Scheier, L. M. (2001).Etiologic Studies of Adolescent Drug Use: A Compendium of Data Resources and Their Implications for Prevention. Journal of Primary Prevention, 22, 125-168. https://doi.org/10.1023/A:1012610002391

Smit, K., Voogt, C., Hiemstra, M., Kleinjan, M., Otten, R., \& Kuntsche, E. (2018). Development of Alcohol Expectancies and Early Alcohol Use in Children and Adolescents: A Systematic Review. Clinical Psychology Review, 60, 136-146. https://doi.org/10.1016/j.cpr.2018.02.002

Stokols, D. (1992). Establishing and Maintaining Healthy Environments: Toward a Social Ecology of Health Promotion. American Psychologist, 4, 6-22. https://doi.org/10.1037/0003-066X.47.1.6

Substance Abuse and Mental Health Services Administration (SAMHSA) (2019). National Survey on Drug Use and Health. Table 2.6B-Alcohol Use in Lifetime, Past Year, and Past Month among Persons Aged 12 or Older, by Detailed Age Category: Percentages, 2002-2019.

https://www.samhsa.gov/data/sites/default/files/reports/rpt29394/NSDUHDetailedTab s2019/NSDUHDetTabsSect2pe2019.htm\#tab2-6b

Trucco, E. M. (2020). A Review of Psychosocial Factors Linked to Adolescent Substance Use. Pharmacology Biochemistry and Behavior, 196, 172969.

https://doi.org/10.1016/j.pbb.2020.172969

Vanessa, H., Moore, K., Ramires, A., \& Mary, A. (2014). An Analysis of State Underage Drinking Policies and Adolescent Alcohol Use. Research Brief, 40, 1-9.

Windle, M. (2000). Parental, Sibling, and Peer Influences on Adolescent Substance Use and Alcohol Problems. Applied Developmental Science, 4, 98-110.

https://doi.org/10.1207/S1532480XADS0402 5

Wong, M. M., Brower, K. J., Fitzgerald, H. E., \& Zucker, R. A. (2004). Sleep Problems in Early Childhood and Early Onset of Alcohol and Other Drug Use in Adolescence. Alcoholism: Clinical and Experimental Research, 28, 578-587. https://doi.org/10.1097/01.ALC.0000121651.75952.39

Yan, F. A., Beck, K. H., Howard, D., Shattuck, T. D., \& Kerr, M. H. (2008). A Structural Model of Alcohol Use Pathways among Latino Youth. American Journal of Health Behavior, 32, 209-219. https://doi.org/10.5993/AJHB.32.2.10

Yu, M., \& Stiffman, A. (2007). Culture and Environment as Predictors of Alcohol Abuse/ Dependence Symptoms in American Indian Youths. Addictive Behavior, 32, 22532259. https://doi.org/10.1016/j.addbeh.2007.01.008 